Received: 18 January 2017

Accepted: 11 May 2017

Published online: 28 June 2017

\section{Determination of Aspergillus pathogens in agricultural products by a specific nanobody-polyclonal antibody sandwich ELISA}

Ting Wang ${ }^{1,2,3}$, Peiwu $\mathrm{Li}^{1,2,3,4,5}$, Qi Zhang ${ }^{1,2,3}$, Wen Zhang ${ }^{1,3,5}$, Zhaowei Zhang ${ }^{1,2,4}$, Tong Wang ${ }^{1,2,3}$ \& Ting $\mathrm{He}^{1,2,3}$

Aspergillus and its poisonous mycotoxins are distributed worldwide throughout the environment and are of particular interest in agriculture and food safety. In order to develop a specific method for rapid detection of Aspergillus flavus to forecast diseases and control aflatoxins, a nanobody, PO8-VHH, highly reactive to $A$. flavus was isolated from an immunized alpaca nanobody library by phage display. The nanobody was verified to bind to the components of extracellular and intracellular antigen from both $A$. flavus and $A$. parasiticus. To construct a sandwich format immunoassay, polyclonal antibodies against Aspergillus were raised with rabbits. Finally, a highly selective nanobody-polyclonal antibody sandwich enzyme-linked immunosorbent assay was optimized and developed. The results revealed that the detection limits of the two fungi were as low as $1 \mu \mathrm{g} \mathrm{mL}^{-1}$, and that it is able to detect fungal concentrations below to $2 \mu \mathrm{g} \mathrm{mg}^{-1}$ of peanut and maize grains in both artificially and naturally contaminated samples. Therefore, we here provided a rapid and simple method for monitoring Aspergillus spp. contamination in agricultural products.

Aspergillus flavus and A. parasiticus are well known producers of aflatoxins, and frequently contaminate agricultural products such as peanut, maize, rice and derived products. The toxins produced by these fungi can cause considerable health risks and significant economic losses due to fungal deterioration of the agricultural commodities $^{1,2}$. It is therefore extremely important to detect and prevent the contamination by Aspergillus species or reduce the level of aflatoxins in grains used in many agricultural products.

Conventional methods for detection of Aspergillus fungi usually rely on plate counting that is laborious and time consuming, moreover, the number of conidia may not reflect actual damage or potential mycotoxin production because aflatoxins are produced by mycelia. Therefore, a better alternative would be required to detect the aflatoxin producers in their early stages of growth before they can produce aflatoxins.

The detection of antigens produced by fungi has enabled the development of simple, rapid, sensitivity and robust detection of specific fungi by using immunological methods $s^{3-6}$. Notermans ${ }^{7}$ showed that detecting mould antigen with ELISA is more reliable, specific, sensitive, simpler to perform, and is able to be used to analysis large number of samples than counting conidia for estimating moulds. And sandwich ELISA has especially advantageous: better capture of antigens, not susceptible to impurities in the sample, and can obtain reliable quantitative relationships ${ }^{8}$. For the past 30 years, immunoassays have been developed for detection of Aspergillus contamination by using polyclonal antisera ${ }^{3,7,9}$, monoclonal antibodies ${ }^{10,11}$ or single-chain variable fragment (scFv) antibodies $^{12-14}$. For $A$. flavus pathogens, however, only monoclonal antibody have been used, with a detection limit in PBS of $1 \sim 2 \mu \mathrm{g} \mathrm{mL}^{-1}$ by ELISA ${ }^{10}$ and $1 \mu \mathrm{gg}^{-1}$ in maize or peanut by a developed scFv antibody fused to $\mathrm{AP}^{14}$.

${ }^{1}$ Oil Crops Research Institute of the Chinese Academy of Agricultural Sciences, Wuhan, 430062, People's Republic of China. ${ }^{2}$ Key Laboratory of Biology and Genetic Improvement of Oil Crops, Ministry of Agriculture, Wuhan, 430062, People's Republic of China. ${ }^{3}$ Key Laboratory of Detection for Mycotoxins, Ministry of Agriculture, Wuhan, 430062, People's Republic of China. ${ }^{4}$ Laboratory of Risk Assessment for Oilseeds Products, Wuhan, Ministry of Agriculture, Wuhan, 430062, People's Republic of China. ${ }^{5}$ Quality Inspection and Test Center for Oilseeds Products, Ministry of Agriculture, Wuhan, 430062, People's Republic of China. Correspondence and requests for materials should be addressed to P.L. (email: peiwuli@oilcrops.cn) or Q.Z. (email: zhangqi01@caas.cn) 


\begin{tabular}{|l|l|l|l|l|}
\hline Antigen & Round & Input(pfu) & Output(pfu) & Ratio(\%) \\
\hline \multirow{4}{*}{ extracellular antigen } & 1 & $6.0 \times 10^{12}$ & $6.0 \times 10^{7}$ & $1.0 \times 10^{-5}$ \\
\cline { 2 - 5 } & 2 & $1.4 \times 10^{13}$ & $1.6 \times 10^{8}$ & $1.2 \times 10^{-5}$ \\
\cline { 2 - 5 } & 3 & $4.0 \times 10^{12}$ & $6.4 \times 10^{8}$ & $1.6 \times 10^{-4}$ \\
\hline \multirow{3}{*}{ mycelia lysate } & 1 & $6.0 \times 10^{12}$ & $7.0 \times 10^{7}$ & $1.2 \times 10^{-5}$ \\
\cline { 2 - 5 } & 2 & $8.0 \times 10^{12}$ & $1.6 \times 10^{8}$ & $2.0 \times 10^{-5}$ \\
\cline { 2 - 5 } & 3 & $3.0 \times 10^{12}$ & $6.0 \times 10^{8}$ & $2.0 \times 10^{-4}$ \\
\hline
\end{tabular}

Table 1. Phages applied and eluted in each round of panning by phage display for extracellular antigens and mycelia lysate. pfu, plaque-forming unit.

In 1993, a group of Belgian scientists found a type of antibody in the blood of camelids (camels, llamas, and alpacas) produce a unique subclass of antibodies that naturally lack light chains, referred to as heavy chain antibody ${ }^{15}$. The variable domain $(\mathrm{VH})$ of such heavy-chain antibodies is formed by only one variable domain $(\mathrm{VHH})$, which contains the antigen binding $\operatorname{site}^{16}$. Recombinant expression of these VHHs yields a single domain heavy-chain antibody, termed "nanobody"17.

Unlike polyclonal and monoclonal antibodies, nanobody can be isolated together with their coding sequence by phage display, expressed with a high yield with a bacterial expression system and readily extracted from the periplasm space while still retaining their monoclonal properties ${ }^{17-19}$. In addition, the low expression yield and poor stability of $s c F v$ limit their development ${ }^{20,21}$, while nanobodies have the advantages of strong stability, good solubility, antigen combined with good performance and low immunogenicity than $\mathrm{scFv}^{22}$. With these benefits, recent success in generating camelid nanobodies prompted our interest in developed and applied for diagnostic and therapeutic purposes ${ }^{23,24}$, and nanobodies are promising reagents in the next generation of immunoassays.

An increasing number of nanobodies, especially in our laboratory, have been isolated against aflatoxin and applied in immunoassay ${ }^{25,26}$. However, as yet not nanobody which have been described against the antigens of $A$. flavus or A. parasiticus have been developed into a specific and sensitive sandwich ELISA, which is able to detect the presence of these fungal species. Based on the facts, we prepared two antigens, extracellular antigens and intracellular antigens (mycelia lysate) of A. flavus, as immunogens to generate nanobodies and rabbit polyclonal antibody, which can recognize certain components of $A$. flavus. After panning, high-affinity Aspergillus-specific nanobodies, EA3-VHH, PO6-VHH and PO8-VHH were successfully isolated from an immunized alpaca nanobody library by phage display. By comparison, $\mathrm{PO} 8-\mathrm{VHH}$, highly selective to A. flavus was finally chosen to develop a sensitive direct sandwich immunoassay for aflatoxigenic Aspergillus pathogens. Immunoblot analyses demonstrated the binding of the $\mathrm{PO} 8 \mathrm{-VHH}$ to the components of extracellular and intracellular antigen from both A. flavus and A. parasiticus. Direct sandwich ELISAs based on the PO8-VHH (capture antibody) and a polyclonal antibody (detection antibody) were developed. The assay is sensitive, accurate, and cost-effective, with limits of detection as low as $1 \mu \mathrm{g} \mathrm{mL}^{-1}$ in PBS and $2 \mu \mathrm{g} \mathrm{mg}^{-1}$ mycelia in peanut or maize, making it suitable for rapid detection of Aspergillus spp. contamination in agricultural products. To the best of our knowledge, this is the first report of the development of a nanobody for direct and species-specific detection of $A$. flavus.

\section{Results}

Antigen preparation and nanobody library. To generate antibodies against aflatoxigenic A. flavus, extracellular antigens and intracellular antigens (mycelia lysate) from a representative strain A. flavus 3.4408 producing high level of aflatoxin were prepared as antigen for immunization of alpaca and rabbit. This strain was identified morphologically and chemically to be an aflatoxin producer as determined by HPLC (data not shown). After the sixth immunization, polyclonal antisera from the immunized alpaca and rabbit antisera were analyzed by indirect ELISA. The results showed a clear robust humoral response up to 1:128000. Total RNA was extracted from immunized alpaca's blood and used to transcribe into cDNA for construction of nanobody library. A phagemid library with a size of $7 \times 10^{8}$ clones was constructed and 20 clones randomly selected were sequenced to evaluate library diversity, which displayed a good diversity and all contained the expected inserts (data not shown) and was subsequently used for panning.

Biopanning and phage ELISA analysis. The constructed phage library containing approximately $10^{12}$ phage particles was screened against extracellular antigens and mycelia lysate of $A$. flavus through three rounds of panning. In order to select phage-displayed VHHs that specifically recognize antigens, washing with PBST was increased each round by five times (10, 15, and 20 times in the first, second and third rounds, respectively), while the amount of antigens coated in plate were fixed. Under such stringent conditions, titer of the output phage was increased steadily after each round of panning, which means an efficient enrichment of specific phage (Table 1). Subsequently, the finally panned library served as a valuable pool for further selection of highly reactive antibodies.

In order to isolate soluble nanobodies with high affinity, 48 clones were randomly selected and affinity of phage- $\mathrm{VHH}$ toward antigens was tested by a phage ELISA. Among them, 4 clones that exhibited a positive reaction toward extracellular antigens and 5 clones toward mycelia lysate of $A$. flavus with varied signal intensity were selected for further analyses (Fig. 1). Sequencing analyses of the selected 4 clones against extracellular antigens from A. flavus showed one group of antibodies: clone 3, 14, 41 and 48 carried identical nucleotide sequences (marked in Fig. 1A). These clones were then named EA3-VHH, and its deduced amino acid sequences were illustrated in Fig. 2A. And sequencing analyses of the selected 5 clones toward mycelia lysate of $A$. flavus were divided 

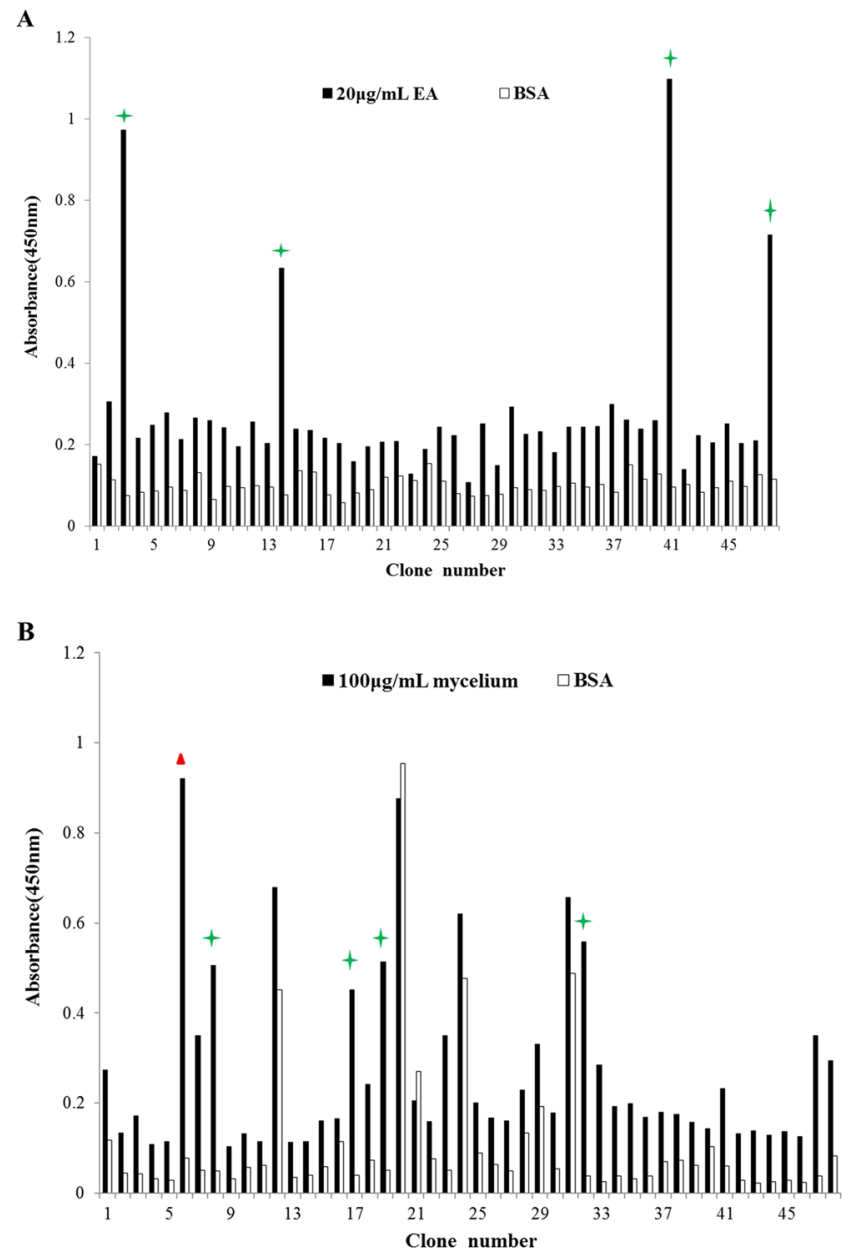

Figure 1. Phage ELISA of randomly selected individual clones toward extracellular antigens (A) and mycelia lysate (B) of A.flavus. Forty-eight clones were selected from the third round of panning and 4 clones showed positive reaction toward extracellular antigens and 5 clones toward mycelia lysate of $A$. flavus with varied signal intensity.

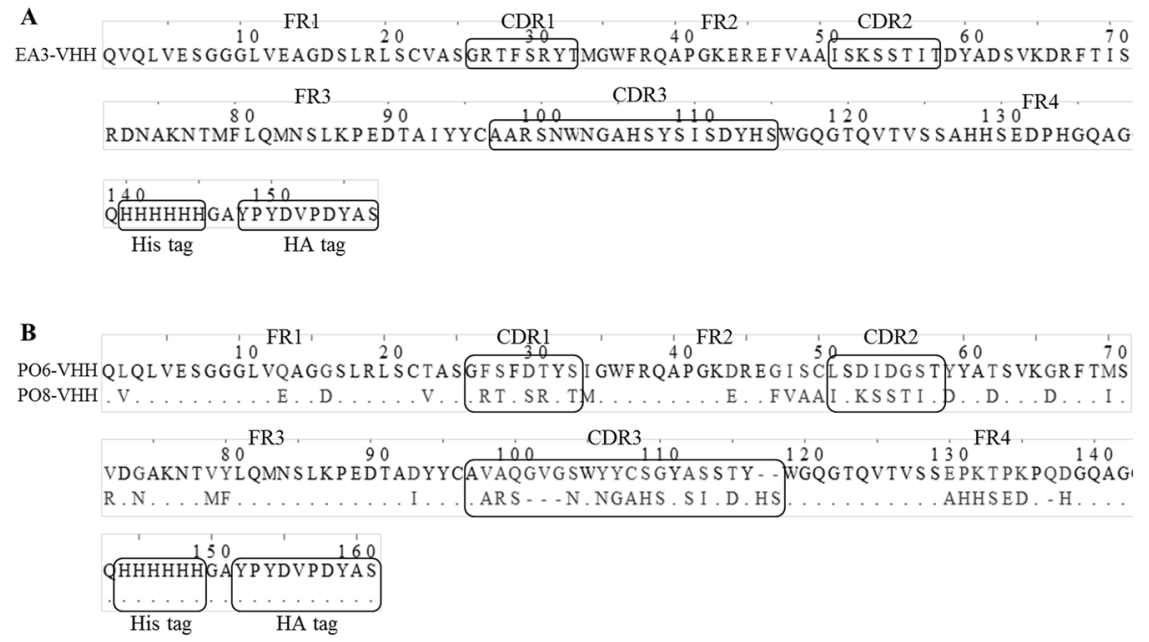

Figure 2. Alignment of amino acid sequences of EA3-VHH (A), PO6-VHH, PO8-VHH (B). Dots indicate identity to the top sequence and dashes indicate absence of amino acid residues compared to the longest sequence. 

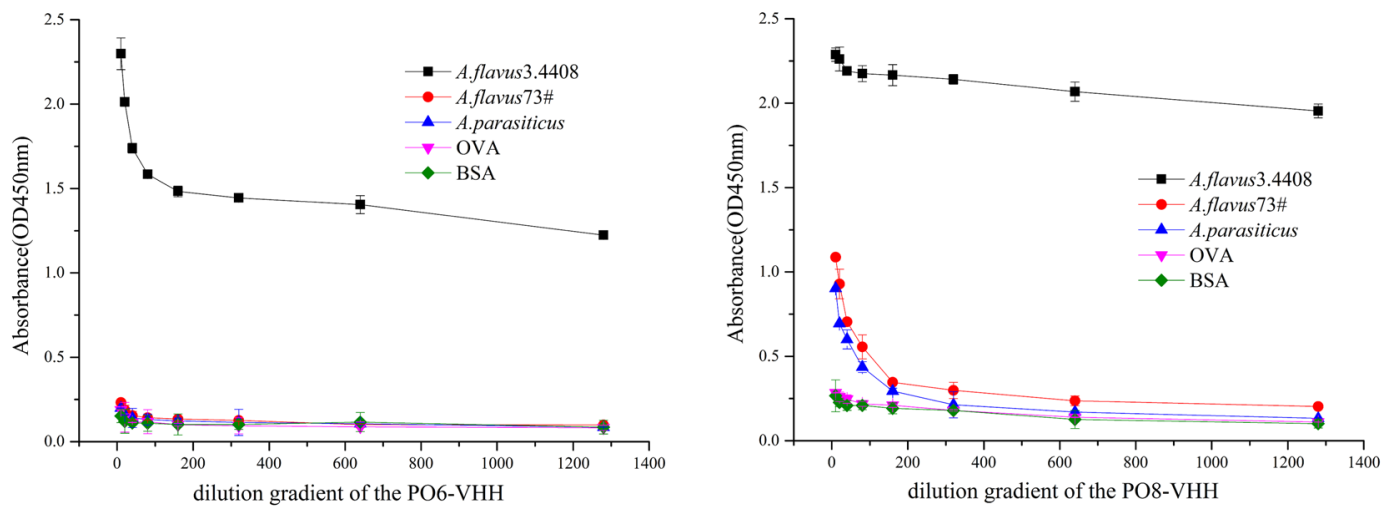

Figure 3. Soluble ELISAs with purified PO6-VHH and PO8-VHH.

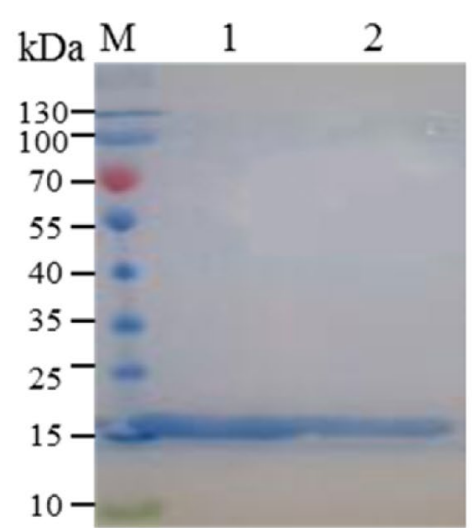

(A)SDS-PAGE

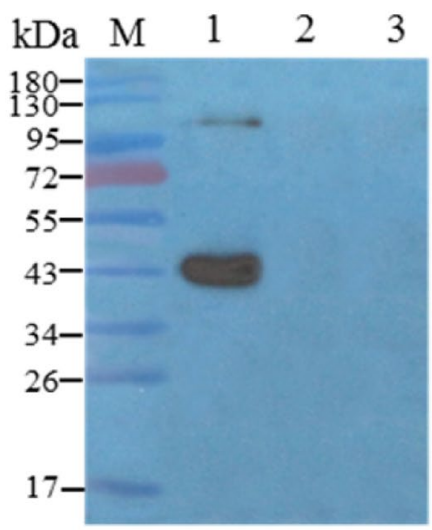

(B)WB of PO6-VHH

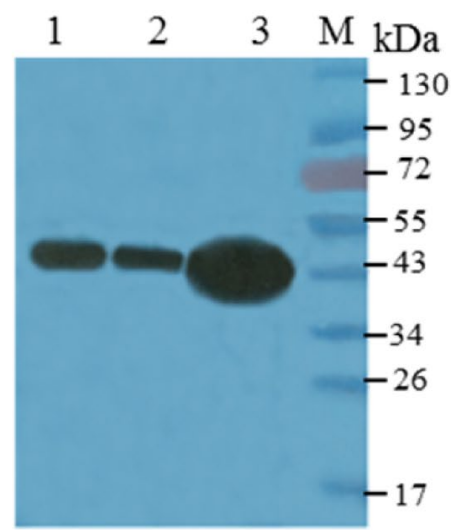

(C)WB of PO8-VHH

Figure 4. SDS-PAGE and Western blotting analysis. (A) SDS-PAGE profile of the purified PO6-VHH (Lane 1) and the purified PO8-VHH (Lane 2). M: Protein Marker. (B) WB profiles of PO6-VHH. 1: A. flavus3.4408; 2: A. flavus73\#; 3: A. parasiticus; M: Protein Marker. (C) WB profiles of PO8-VHH.1: A. flavus73\#; 2: A. parasiticus; 3: A. flavus3.4408; M: Protein Marker.

into two groups of antibodies: clone 8,17, 19 and 32 contained identical sequences; clone 6 carried different nucleotide sequence (marked in Fig. 1B). These clones were then named PO6-VHH and PO8-VHH, respectively, and their deduced amino acid sequences were illustrated in Fig. 2B. However, further sequence analysis of these three nanobodies showed that EA3-VHH and PO8-VHH carried identical nucleotide sequences. Therefore, the phage-displayed PO6-VHH and PO8-VHH were confirmed to be originated from alpaca and were used for further characterization.

Soluble nanobody ELISA and immunoblot analysis. To further reveal their binding activity toward A. flavus and A. parasiticus that also produced aflatoxins (data not shown), soluble ELISAs with two nanobodies purified from large-scale expression were carried out. The results confirmed that both still had the highest reactivity to A. flavus 3.4408, whereas the PO6-VHH had lowest reactive to A. flavus73\# and A. parasiticus (Fig. 3). Meanwhile, PO8-VHH has a better binding ability to A. flavus73\# and A. parasiticus than PO6-VHH. These results suggested that CDRs in the $\mathrm{PO} 8 \mathrm{-VHH}$, with variation in both the sequence and length, may play an important role in its interaction with antigens resulting in the highest binding activity.

For further analyses of antigen-binding properties of the PO6-VHH and PO8-VHH, the mycelia from other A. flavus and A. parasiticus isolated from diseased peanut in China were detected by immunoblots, and the results showed that PO8-VHH could bind to the same antigen displayed a single band (45-kDa) in A. flavus and A. parasiticus, whereas the PO6-VHH could only bind to the antigen in A. flavus 3.4408 but not bind to other A. flavus and A. parasiticus (Fig. 4). These results further indicated that the PO8-VHH apparently contributes a proper structural conformation and is most specific to the antigen that is commonly and constitutively present on fungal mycelia of both $A$. flavus and A. parasiticus, although the precise component recognized by the nanobody is unknown. Therefore, the PO8-VHH may be a proper candidate for further genetic manipulation for wide use in immunoassays.

To further evaluate the specificity of the PO8- $\mathrm{VHH}$, ten isolates of Aspergillus with different levels aflatoxin and other fungal or bacteria species (Table 2) were used for indirect ELISA analysis. The results indicated that the PO8-VHH had a high affinity for Aspergillus, especially for A. flavus and A. parasiticus but did not cross-react 


\begin{tabular}{|l|l|l|}
\hline Species & $\begin{array}{l}\text { PO8-VHH for } \\
\text { different fungi }\end{array}$ & Aflatoxin $\mathbf{B}_{\mathbf{1}}\left(\boldsymbol{\mu} \mathbf{~ L}^{-1}\right)^{\mathbf{b}}$ \\
\hline A. flavus3.4408 & 2.608 & 186.49 \\
\hline A. flavus73\# & 2.088 & 139.94 \\
\hline A. flavus271\# & 1.870 & 115.76 \\
\hline A. flavus233\# & 2.345 & 38.18 \\
\hline A. flavus321\# & 2.149 & - \\
\hline A. flavus3.2572 & 1.828 & - \\
\hline A. parasiticus & 2.028 & 193.43 \\
\hline A. versicolor & 0.757 & - \\
\hline A. niger & 0.168 & - \\
\hline A. fumigatus & 0.145 & - \\
\hline Fusarium-1 & 0.093 & - \\
\hline Fusarium-2 & 0.099 & - \\
\hline Fusarium oxysporum & 0.086 & - \\
\hline Penicillum citrinum & 0.080 & - \\
\hline Penicillum chrysogenum & 0.079 & - \\
\hline Rhizoctonia-1 & 0.075 & - \\
\hline Rhizoctonia-2 & 0.078 & - \\
\hline Trichoderma & 0.085 & - \\
\hline Yeast & 0.086 & - \\
\hline Escherichia coli & 0.072 & - \\
\hline & & \\
\hline
\end{tabular}

Table 2. Affinity and specificity of PO8-VHH determined by ELISA analyses. ${ }^{\text {aPlate }}$ wells were coated with mycelia of different fungal or bacteria species, followed by adding PO8-VHH. For wells containing the PO8-VHH, mouse anti-HA antibody and HRP-labeled goat anti-mouse antibody were additionally added. Colorimetric reactions were performed by adding TMB substrate and measured the absorbance at $450 \mathrm{~nm}$. Each sample was carried out in triplicate and the scale presents an arbitrary set of the mean of $\mathrm{OD}_{450 \mathrm{~nm}}$ readings. ${ }^{b}$ Aflatoxins $\mathrm{B}_{1}$ were determined by HPLC. Aspergillus and other fungal or bacteria species were cultured in Czapek medium at $28^{\circ} \mathrm{C}$ for 5 days.

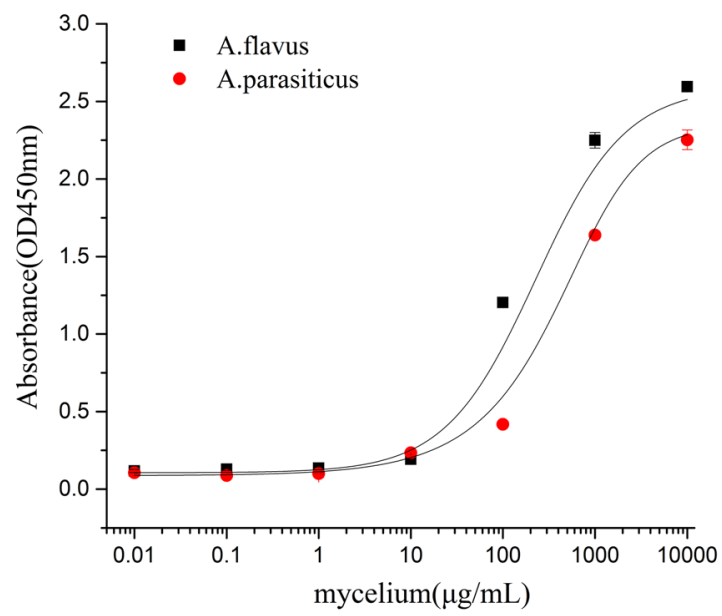

Figure 5. The sensitivity and detection limits of PO8-VHH determined with different concentrations of $A$. flavus and A. parasiticus. $100 \mu \mathrm{L}$ of $A$. flavus or A. parasiticus was grinded and diluted in PBS at indicated concentrations and added into plate wells for indirect ELISA detection with $200 \mathrm{nM}$ purified soluble PO8-VHH. Values represent mean \pm SD of triplicate assays.

with other fungal or bacteria species (Table 2). These results congruously suggested that the PO8-VHH is specific to Aspergillus genus and can be able to specifically detect Aspergillus in the condition of complex pollution of different fungal pathogens, as Tsai pointed out that antibodies against moulds are specific at the genus level and only react to closely related genera ${ }^{3}$.

To evaluate the affinity of the PO8-VHH, the detection limit of the PO8-VHH $\left(200 \mathrm{nM} \approx 4 \mu \mathrm{g} \mathrm{mL} \mathrm{m}^{-1}\right)$ was measured by indirect ELISA with different fungal concentrations. As shown in Fig. 5, the detection limit of PO8-VHH 


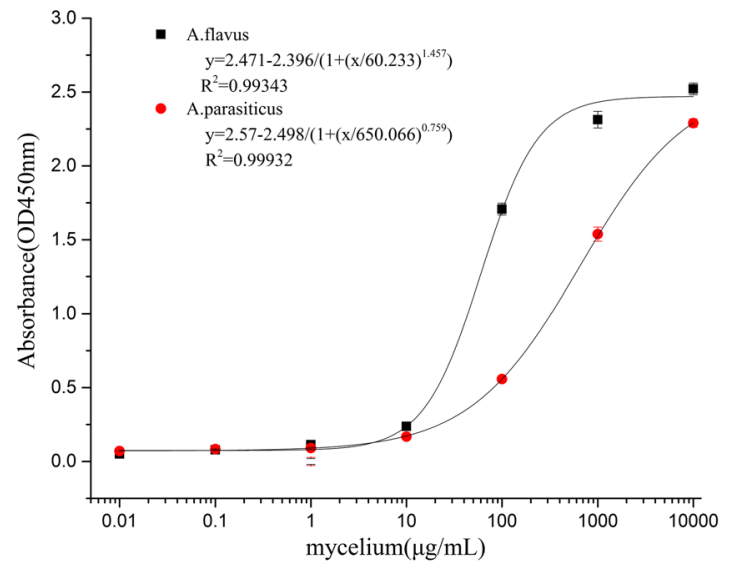

Figure 6. The sensitivity and detection limits of $\mathrm{PO} 8 \mathrm{-VHH}$ as capture antibody and polyclonal antibody as detection antibody in sandwich ELISA with different concentrations of A. flavus and A. parasiticus. $100 \mu \mathrm{L}$ of PO8-VHH $\left(0.5 \mu \mathrm{g} \mathrm{mL}^{-1}\right)$ was coated into the plate wells, followed by addition of $100 \mu \mathrm{L}$ of $A$. flavus or $A$. parasiticus that was grinded and diluted in PBS at indicated concentrations, and then $100 \mu \mathrm{L}$ of polyclonal antibody $\left(1 \mu \mathrm{g} \mathrm{mL}^{-1}\right)$ was added for detection. Values represent mean $\pm \mathrm{SD}$ of triplicate assays.

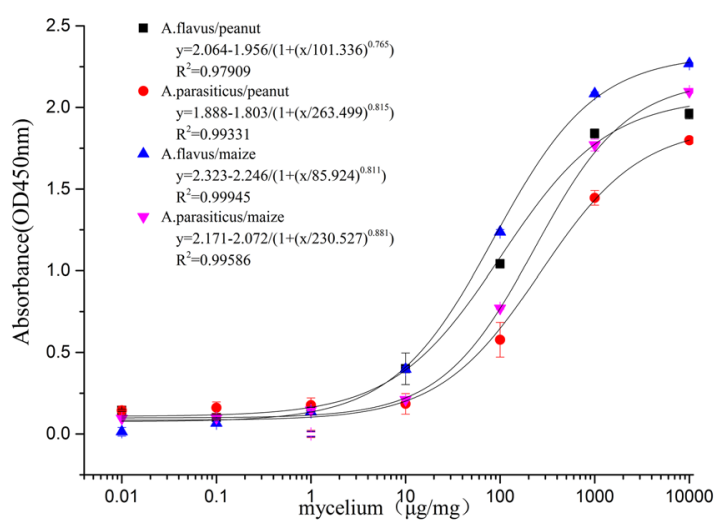

Figure 7. The limits of quantifications of $A$. flavus and A. parasiticus in peanut and maize determined by sandwich ELISA. $100 \mu \mathrm{L}$ of PO8-VHH was coated into plate wells, followed by addition of $100 \mu \mathrm{L}$ mixtures of A. flavus-peanut, A. parasiticus-peanut, A. flavus-maize, and A. parasiticus-maize at indicated concentrations. Then $100 \mu \mathrm{L}$ of polyclonal antibody was added for detection. Values represent mean \pm SD of triplicate assays.

towards A. flavus and A. parasiticus was about $10 \mu \mathrm{g} \mathrm{mL}^{-1}$. Therefore, the PO8-VHH expressed in E. coli can be better used for detecting aflatoxigenic Aspergillus pathogens directly and simply.

Standard curve of the sandwich ELISA. To optimize sandwich ELISA detection through the PO8-VHH and polyclonal antibody, the capture antibody and detection antibody were compared for their applicability and sensitivity. The A. flavus and A. parasiticus mycelia with different concentrations in PBS $\left(0,10^{-2}, 10^{-1}, 1,10,10^{2}\right.$, $\left.10^{3}, 10^{4} \mu \mathrm{g} \mathrm{mL}^{-1}\right)$ were used to construct a standard curve. Additionally, a standard curve for the polyclonal antibody (capture antibody) and PO8-VHH (detection antibody) was also constructed, but the value of blank was so high no matter how optimized the concentration (data not shown). Finally, a standard curve for the PO8-VHH (capture antibody) at $0.5 \mu \mathrm{g} \mathrm{mL}^{-1}$ combined with polyclonal antibody (detection antibody) at $1 \mu \mathrm{g} \mathrm{mL}^{-1}$ was con-

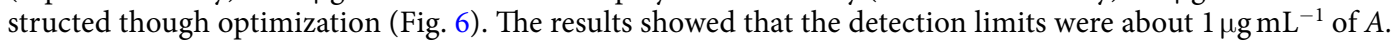
flavus and A. parasiticus for sandwich ELISA.

Sandwich ELISA for rapid immunological detection of Aspergillus contamination in agricutural products. To determine the limit of quantification, different concentrations of mycelia from A. flavus 3.4408 and $A$. parasiticus mixed with grinded peanut or maize $\left(1 \mathrm{mg} \mathrm{mL}^{-1}\right)$ were prepared, and the homogenates were assayed by the optimized sandwich ELISA.

The results showed that the detection limit for the PO8-VHH and polyclonal antibody was approximately $2 \mu \mathrm{g} \mathrm{mg}^{-1}$, which was identical to the detection limit in PBS but with a lower and slower color development (Fig. 7). Under the optimized sandwich ELISA condition, the fungal concentration displayed a good correlation between logarithmic concentration of mycelia and $\mathrm{OD}_{450 \mathrm{~nm}}$ values $\left(\mathrm{R}^{2}>0.99\right.$ for both fungi).

To study the feasibility of PO8-VHH combined with polyclonal antibody for rapid immunological detection, sandwich ELISA was used to detect naturally Aspergillus contaminated peanut and maize samples collected 


\begin{tabular}{|c|c|c|}
\hline Sample & $\begin{array}{l}\text { ELISA for Aspergillus pathogens } \\
\text { (absorbance at } 450 \mathrm{~nm} \text { ) }\end{array}$ & $\begin{array}{l}\text { Concentration of } \\
\text { aflatoxin } B_{1}\left(\mu \mathrm{g} \mathrm{kg}^{-1}\right)^{f}\end{array}$ \\
\hline CK-peanut $^{\mathrm{a}}$ & 0.109 & - \\
\hline CK-maize $^{\mathrm{a}}$ & 0.086 & - \\
\hline AF-peanut $^{\mathrm{b}}$ & 0.517 & 1767.274 \\
\hline AF-maize ${ }^{\mathrm{b}}$ & 0.712 & 1639.935 \\
\hline AP-peanut ${ }^{\mathrm{c}}$ & 0.678 & 1449.408 \\
\hline AP-maize ${ }^{c}$ & 0.619 & 1513.999 \\
\hline $\mathrm{JX} 31^{\mathrm{d}}$ & 0.346 & 826.128 \\
\hline $\mathrm{JX} 32^{\mathrm{d}}$ & 0.241 & 143.289 \\
\hline $\mathrm{FJ}_{5} 4^{\mathrm{d}}$ & 0.447 & 1016.201 \\
\hline FJ56 ${ }^{\mathrm{d}}$ & 0.382 & 915.221 \\
\hline $\mathrm{GX}^{\mathrm{d}} 3^{\mathrm{d}}$ & 0.169 & 44.729 \\
\hline GX74 & 0.344 & 1088.759 \\
\hline $\mathrm{GX}^{\mathrm{d}} 8^{\mathrm{d}}$ & 0.434 & 1079.568 \\
\hline HLJ98 $^{\mathrm{d}}$ & 0.353 & 1026.486 \\
\hline $\mathrm{HB}^{106^{\mathrm{d}}}$ & 0.410 & 761.764 \\
\hline GD $110^{\mathrm{d}}$ & 0.259 & 326.638 \\
\hline GX49e & 0.233 & 1060.888 \\
\hline GX51 $1^{\mathrm{e}}$ & 0.504 & 1226.094 \\
\hline GX54 & 0.179 & 641.554 \\
\hline GX59 & 0.329 & 931.604 \\
\hline GX259e & 0.442 & 787.524 \\
\hline GX341 ${ }^{\mathrm{e}}$ & 0.279 & 830.445 \\
\hline
\end{tabular}

Table 3. Aspergillus-contaminated peanut and maize samples collected from different areas in China and

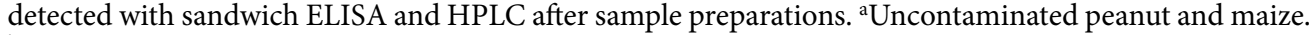
${ }^{b}$ Peanut and maize were inoculated with $A$. flavus 3.4408 used in this study and cultured at $28^{\circ} \mathrm{C}$ for 10 days. 'Peanut and maize were inoculated with $A$. parasiticus used in this study and cultured at $28^{\circ} \mathrm{Cfor} 10$ days. ${ }^{\mathrm{d}}$ Aspergillus-infected peanut from stocks collected from different provinces, China. ${ }^{\mathrm{e}}$ Aspergillus-infected maize from stocks collected from Guangxi(GX) province, China. ${ }^{f}$ Aflatoxins $B_{1}$ were determined by HPLC. Each sample was carried out in triplicate and the scale presents an arbitrary set of the mean of $\mathrm{OD}_{450 \mathrm{~nm}}$ readings.

from different areas in China and 4 artificially samples inoculated with A. flavus and A. parasiticus, respectively (Table 3). The results indicated that both samples can be detected effectively without any false-positive signals in the healthy peanut and maize. Therefore, sandwich ELISA based on the prokaryote-expressed PO8-VHH may be preferable for monitoring naturally Aspergillus-contaminated samples in agricultural products.

\section{Discussion}

In this study, two kinds of antigens, extracellular antigens and intracellular antigens (mycelia lysate) from $A$. fla$v u s$ were designed to include the surface proteins and crude extract proteins of A. flavus. In order to obtain high affinity nanobodies for $A$. flavus, we first explored the dose of antigens immunized rabbits to get high titer alpaca antiserum. Results indicate that about $1 \mathrm{mg} \mathrm{mL}^{-1}$ extracellular antigens and $100 \mathrm{mg} \mathrm{mL}^{-1}$ mycelia lysate (fungal concentration) were confirmed as good immunogen for eliciting antibodies.

In order to select phage-displayed VHHs that specifically recognize antigens, a optimized solid phase protocol was performed to select the nanobodies through 3 rounds of panning. Washing with PBST was increased each round by five times, while the amount of antigens coated in plate were fixed so as to efficient enrichment of selective phage. Finally, EA3-VHH, PO6-VHH and PO8-VHH were successfully isolated and cloned the gene of a high-affinity Aspergillus-specific nanobody from an immunized alpaca antibody library by phage display. By comparison, EA3-VHH and PO8-VHH carried identical nucleotide sequences. It is speculated that PO8-VHH recognized protein of $A$. flavus could be easily secreted and therefore easily detected. Therefore, it is possible to detect A. flavus in the samples, and this nanobody could be used to establish an immunosensor assay for detection of the samples. And results of both soluble nanobody ELISA and sandwich ELISA showed that PO8-VHH could recognizes an antigen that both exist in extracellular and intracellular of A. flavus and A. parasiticus. Specificity and reactivity assays indicated that the PO8-VHH had binding for all Aspergillus species and had no cross-reactivity with non-Aspergillus species.

Moreover, a nanobody-polyclonal antibody sandwich ELISA based on the PO8-VHH was optimized and developed. This assay was able to detect the fungus at a concentration as low as $1 \mu \mathrm{g} \mathrm{mL}^{-1}$, the same magnitude as reported by others ${ }^{10}$. It is a pity that the detection limit in peanut and maize was a fungal concentration of $2 \mu \mathrm{g} \mathrm{mg}^{-1}$, with less sensitivity than that reported $\left(1 \mu \mathrm{gg}^{-1}\right)$ thus far ${ }^{14}$. Although the sensitivity is not as good as that of $\mathrm{scFv}^{14}$, but as others have reported ${ }^{20,21}$, the nanobody is more stable than $\mathrm{scFv}$ and has so small molecular weight $(15-\mathrm{kDa})$, and the most important advantage of nanobody is that it has strong and fast tissue penetration, which is able to enter the dense tissue such as solid tumors to play a role ${ }^{27,28}$. As we have shown in Fig. 4, it is found that PO8-VHH could bind to the same antigen displayed a single band (45-kDa) in A. flavus and A. 
parasiticus, which is of great value for exploring target molecules in Aspergillus pathogens by using the advantage of penetrate the cell membrane. We will use the immunoaffinity column to enrich the single component and determine the target molecule by mass spectrometry in next studies. Of course, we will also be committed to developing a more sensitive method based on PO8-VHH, such as the construction of AP-labeled functional nanobodies, to improve the detection limit of $A$. flavus in future work.

When sandwich ELISA and the HPLC method were used to evaluate samples that were naturally contaminated with aflatoxins, A. flavus antigens were detected in all samples containing aflatoxins (Table 3 ). Therefore, the sandwich ELISA would have potential to detect aflatoxigenic Aspergillus in naturally contaminated samples. We found that there is still a certain regularity here: for example, samples GX73 and GX54 showed the lowest ELISA signal, and their aflatoxins were lowest; the ELISA signal of samples AF-inoculated, AP-inoculated and GX51 were top three, and their aflatoxins also ranked the top three. However, we also found that ELISA and aflatoxin levels determined by HPLC did not correspond totally in this study because there were instances when high levels of aflatoxin samples showed low ELISA readings in Table 3. This result may be due to the differences in substrate composition and growth conditions (temperature, $\mathrm{pH}$, water activity) since they were collected from different sources that affect aflatoxin levels ${ }^{29}$.

In summary, we have developed a sandwich ELISA based on a nanobody and polyclonal antibody which is selective for effectively detecting aflatoxin producing strains of Aspergillus spp. in agricultural products. This method is likely to be useful for detecting the fungi before they are mature enough to produce high levels of aflatoxin. Thus this is an excellent early detection system. To our knowledge, this is the first example of the development of a nanobody for detection of Aspergillus pathogens.

\section{Materials and Methods}

Materials, culture media and buffers. A representative fungal strains A. flavus 3.4408 purchased from China Center for Microbial Culture Collection, is a wild-type, aflatoxin-producing strain. Other fungi (Table 2) were conserved in our laboratory. Escherichia coli ER2738 competent cells were purchased from Lucigen Corp. (Middleton, WI, USA), Top $10 \mathrm{~F}^{\prime}$ competent cells was obtained from Life Technologies (Grand Island, NY). Complete and incomplete Freund's adjuvant, 3,3,5,5-tetramethylbenzidine (TMB), goat anti-mouse IgG antibody conjugated to horseradish peroxidase (HRP), and HRP-labeled goat anti-rabbit IgG antibody were purchased from Sigma Company (St. Louis, MO, USA). HRP-labeled mouse anti-M13 monoclonal antibody was purchased from GE Healthcare (Piscataway, NJ, USA). Anti-HA tag mouse monoclonal antibody was purchased from ComWin Biotech (Beijing, China). Helper phage M13KO7 and SfiI were obtained from New England Biolabs (Ipswich, MA, USA). pComb3X phagemid vector was a generous gift from Dr. Carlos F. Barbas (The Scripps Research Institute, La Jolla, CA). LeukoLOCK total RNA isolation system was obtained from Applied Biosystems (Foster City, CA). QIAprep Spin MiniPrep Kit, QIAquick Gel Extraction Kit and QIAquick PCR Purification Kit were all from Qiagen. xTractor buffer for protein extraction and Ni-NTA chromatography resin were purchased from Clontech Laboratories, Inc. (Mountain View, CA, USA). The Costar 96-well EIA/RIA plate was purchased from Corning Incorporated (Corning, NY, USA).

Fungal culture: Czapek medium (3\% (w/v) sucrose, 0.3\% (w/v) $\mathrm{NaNO}_{3}, 0.1 \%(\mathrm{w} / \mathrm{v}) \mathrm{K}_{2} \mathrm{HPO}_{4}, 0.05 \%(\mathrm{w} / \mathrm{v})$ $\mathrm{MgSO}_{4} \cdot 7 \mathrm{H}_{2} \mathrm{O}, 0.05 \%$ (w/v) $\mathrm{KCl}, 0.001 \%$ (w/v) $\left.\mathrm{FeSO}_{4}, \mathrm{pH}^{2} .5\right)$.

The following buffers were used: (1) $0.01 \mathrm{M}$ phosphate buffered saline (PBS, $\mathrm{pH} 7.4$ ) was prepared by adding $8 \mathrm{~g}$ of $\mathrm{NaCl}, 2.9 \mathrm{~g}$ of $\mathrm{Na}_{2} \mathrm{HPO}_{4} \cdot 12 \mathrm{H}_{2} \mathrm{O}, 0.2 \mathrm{~g}$ of $\mathrm{KH}_{2} \mathrm{PO}_{4}$ and $0.2 \mathrm{~g}$ of $\mathrm{KCl}$ in $1000 \mathrm{~mL}$ deionized water, (2) coating buffer was $0.025 \mathrm{M}$, pH 9.6 carbonate buffer, (3) washing buffer was PBS containing $0.05 \%$ Tween 20 (v/v) (PBST), (4) block buffer was $5 \%$ skimmed milk (m/v) in PBST, (5) substrate solution system was composed by $9.5 \mathrm{~mL} \mathrm{pH}$ 5.0 phosphate-citrate buffer, $0.5 \mathrm{~mL} 2 \mathrm{mg} \mathrm{mL}^{-1} \mathrm{TMB}$ (dissolved by ethanol) and $32 \mu \mathrm{L} 3 \%(\mathrm{w} / \mathrm{v}$ ) urea hydrogen peroxide, (6) stop solution was $2 \mathrm{M} \mathrm{H}_{2} \mathrm{SO}_{4}$.

Unless otherwise stated, all other chemicals and organic solvents were of analytical reagent grade or better. Water was obtained from a MilliQ purification system (Millipore).

Safety. This study involving the care and use of animals was carried out in strict accordance with the recommendations in the Guide for the Care and Use of Laboratory Animals of the National Institutes of Health. The protocol was approved by the Laboratory Animal Monitoring Committee of Hubei Province and performed accordingly.

Pure aflatoxin standards were handled in a hood with extreme caution. All items coming in contact with aflatoxins, phage and bacterial cultures (glassware, vials, tubes, ELISA plates, etc.) were immersed in a $10 \%$ bleach solution for $1-2 \mathrm{~h}$ before they were discarded or autoclaved.

Antigen preparation and immunization. A representative isolate of A. flavus 3.4408, a potential aflatoxin producer was used for antigen preparation. The mycelia were cultured in Czapek medium on a shaker (200 rpm) at $28^{\circ} \mathrm{C}$ for 5 days. The mycelia were harvested by filtration through four layers of cheesecloth. Extracellular antigens in the medium were prepared according to Tsai and Cousin ${ }^{3}$. In brief, the cultural fluid was separated by filtration and then through a $0.45-\mu \mathrm{m}$ membrane. The filtrate was extracted with $80 \%$ saturated ammonium sulfate by stirring for $2 \mathrm{~h}$ at $4^{\circ} \mathrm{C}$. After the precipitate was suspended in PBS and then dialyzed overnight, the filtrate was concentrated and the concentration was determined. Intracellular antigens (mycelia lysate) prepared according to the method of Yong and Cousin ${ }^{6}$. For the preparation of mycelia lysate, mycelia were suspended in PBS with a final concentration of $3.7 \%$ formalin solution. After inactivation overnight at $4{ }^{\circ} \mathrm{C}$, the mycelia were then frozen immediately in liquid nitrogen and grinded into fine powder. The powdered mycelia were weighed and suspended in PBS buffer. The suspended mycelia were homogenized for 3 times in a high pressure homogenizer ATS 1500 at 100 bar and further up to 1000 bar for 4 times so as to fully disrupt mycelia. Disruptions of mycelia were confirmed by electron microscope. 
A 2-year-old male alpaca was immunized subcutaneously with $1 \mathrm{mg} \mathrm{mL}^{-1}$ extracellular antigens and $100 \mathrm{mg} \mathrm{mL}^{-1}$ mycelia lysate (fungal concentration) mixed with the same volume of Freund's complete Adjuvant. Five additional injections were given at 2 -week intervals. After the last booster, $2 \times 10$ milliliters blood was used for mRNA extraction.

The New Zealand White female rabbit was injected intramuscularly with similar method of alpaca. Boosters were given every other week for a total of six times. Seven days after the final injection, the rabbit was bled to collect whole blood and antiserum. Immunoglobulin $\mathrm{G}(\mathrm{IgG})$ was purified from the antiserum using octanoic acid-saturated ammonium sulfate precipitation ${ }^{30}$. Then, the purified polyclonal antibody was freeze-dried and stored at $-20^{\circ} \mathrm{C}$.

Preimmune serum was collected as a negative control. The antibody titers were assayed by indirect ELISA.

Phage-displayed Library Construction. According to the titer results, the sixth blood was selected to extract RNA and construct the library. The library was constructed as previously described ${ }^{24}$. In brief, total RNA was extracted from alpaca's blood and transcribed into cDNA. Nanobody gene fragments encoding the VHH variable domains were amplified by PCR using a previously published procedure ${ }^{31}$. Two pairs of primers containing two different SfiI sites (underlined) are as followed, forward primer VHH-F (CAT GCC ATG ACT GTG GCC CAG GCG GCC CAG KTG CAG CTC GTG GAG TC) targeting the framework 1 region, reverse primers VHH-R1 (CAT GCC ATG ACT CGC GGC CGG CCT GGC CGT CTT GTG GTT TTG GTG TCT TGG G) and VHH-R2 (CAT GCC ATG ACT CGC GGC CGG CCT GGC CAT GGG GGT CTT CGC TGT GGT GCG) corresponding to the IgG2 and IgG3 hinge region, respectively. The PCR products and pComb3X phagemid vector were separately digested with SfiI and subsequently ligated to generate pComb3X/nanobody constructs. The resulting recombinant phagemids were transformation into the competent cells of E. coli ER 2738. The cells were then plated on LB ampicillin agar plates to estimate the library size. Twenty clones were selected from the LB-amp plate and sequenced to evaluate library diversity.

Panning. The constructed phage library containing approximately $10^{8}$ phage particles was screened against $A$. flavus through three rounds of panning. A solid phase protocol was performed to select the nanobodies with high affinity. Briefly, the wells were washed with PBST increased five times in each round (10,15 and 20 times in the first, second and third rounds, respectively), while the amount of antigens were fixed. Under these stringent conditions, the ratios of output and input phages increased steadily (Table 1), with about 10-fold increased phage recovery after the third round of panning compared with the first one, demonstrating an efficient enrichment of specific antibodies. After three rounds of panning, 48 clones were randomly selected from the final output titer plate and infected with M13KO7 helper phage for further characterized by phage enzyme-linked immunosorbent assay (ELISA). Clones binding to antigens but not to any other protein like BSA or OVA were deemed positive and selected for further analyses.

Sequencing analysis of nanobodies. The rescued phages were applied to phage ELISA with $1 \mathrm{mg} \mathrm{mL}^{-1}$ antigens as previously described ${ }^{32}$. Plasmid DNAs from the positive clones were extracted and sequenced using the primer gback (GCCCCCTTATTAGCGTTTGCCATC).

Soluble nanobody ELISA. Soluble nanobodies were expressed in bacteria as previously described ${ }^{26}$.

The antigen-binding characteristics of nanobodies were identified by indirect ELISA. The protocol for indirect ELISA was similar to that described by $\mathrm{Hu}$ et al..$^{32}$ with slight modification.

96-well microtiter plates were respectively coated with $100 \mu \mathrm{L}$ of $100 \mu \mathrm{g} \mathrm{mL}^{-1}$ extracellular antigens and mycelia lysate from $A$. flavus and A. parasiticus in PBS per well overnight at $4^{\circ} \mathrm{C}$ and blocking with $5 \%$ skimmed milk in PBS at $37^{\circ} \mathrm{C}$ for $2 \mathrm{~h}$. After three times washing with PBST, $200 \mathrm{nM}$ purified nanobodies was added to each well and incubated for $1 \mathrm{~h}$ at $37^{\circ} \mathrm{C}$. After three washing cycles, $100 \mu \mathrm{L}$ of anti-HA mouse monoclonal antibody was added to each well following by $1 \mathrm{~h}$ incubation at $37^{\circ} \mathrm{C}$. Then the plate wells were incubated with $100 \mu \mathrm{L}$ of HRP-labeled goat anti-mouse IgG antibody for $1 \mathrm{~h}$ at $37^{\circ} \mathrm{C}$. After washing, $100 \mu \mathrm{L}$ peroxidase substrate solution system were incubated for $15 \mathrm{~min}$ at $37^{\circ} \mathrm{C}$. Enzyme reactivity was stopped by adding $50 \mu \mathrm{L}$ of $2 \mathrm{M} \mathrm{H}_{2} \mathrm{SO}_{4}$ and the absorbance was detected at $450 \mathrm{~nm}$ by a microplate reader. Some other protein like BSA or OVA served as the control.

To further evaluate the specificity of the nanobody, ten isolates of Aspergillus spp. with different level aflatoxin and other genera of fungi or bacteria were used for indirect ELISA analysis. The remaining steps were performed the same as soluble nanobody-ELISA.

Sensitivities of nanobodies were measured by an indirect ELISA. Different concentrations of $A$. flavus and $A$. parasiticus grinded in PBS $\left(10^{-2}, 10^{-1}, 1,10,10^{2}, 10^{3}, 10^{4} \mu \mathrm{g} \mathrm{mL}^{-1}\right)$ were added into plate wells and detected with $200 \mathrm{nM}$ nanobodies in indirect ELISA.

Immunoblot analysis of nanobody. Immunoblots of extracellular antigens and mycelia from $A$. flavus and $A$. parasiticus was detected with nanobodies. In immunoblot assays, extracellular antigens and mycelia of $A$. flavus and A. parasiticus boiled for 5 min were applied to $12 \%(\mathrm{w} / \mathrm{v})$ SDS-PAGE and then transferred onto nitrocellulose membrane (Millipore). The membrane was washed with TBST three times for $15 \mathrm{~min}$ and then blocked with $5 \%$ non-fat milk for $1 \mathrm{~h}$ at room temperature, followed by incubation with nanobodies (100 $\mathrm{nM})$ for $2 \mathrm{~h}$. After incubating with the nanobody solution and washed with TBST, the membranes were followed by addition of anti-HA mouse antibody (1:1000 dilution) and HRP-labeled goat anti-mouse IgG antibody (1:2000 dilution) for $1 \mathrm{~h}$ at room temperature, respectively.

The membrane was then washed and incubated with ECL (USA) solution in a dark room for $10 \mathrm{~min}$. 
Detection of $A$. flavus by sandwich ELISA. A sandwich ELISA procedure requires testing match pair antibodies, capture and detection antibodies that detect different epitopes on the target antigen so that they do not interfere with the other antibody binding. To optimize sandwich ELISA match pair antibodies through the nanobody and polyclonal antibody, the capture antibody and detection antibody were compared for their applicability and sensitivity.

Different concentrations of mycelia from A. flavus and A. parasiticus ranging from approximately $10^{-2}$ to $10^{4}$ $\mu \mathrm{g} \mathrm{mL}^{-1}$ were determined by a sandwich ELISA according to the following protocol: 96 -well microtiter plates were coated with $100 \mu \mathrm{L}$ of capture antibody (nanobody) at $0.5 \mu \mathrm{g} \mathrm{mL}^{-1}$ at $4{ }^{\circ} \mathrm{C}$ overnight; three times washing with PBST were performed and each well was blocked with $300 \mu \mathrm{L}$ of $5 \%$ non-fat milk at $37^{\circ} \mathrm{C}$ for $2 \mathrm{~h}$; after three times washing with PBST, $100 \mu \mathrm{L}$ of ten-fold serial diluted mycelia (A. flavus and A. parasiticus) were added at $37^{\circ} \mathrm{C}$ for $1 \mathrm{~h}$; washing cycles were repeated and $100 \mu \mathrm{L}$ of the polyclonal antibody at $1 \mu \mathrm{g} \mathrm{mL}^{-1}$ was added and incubated at $37^{\circ} \mathrm{C}$ for $1 \mathrm{~h}$; after washing, $100 \mu \mathrm{L}$ HRP-labeled goat anti-rabbit IgG antibody (1:10000 dilution) was incubated at $37^{\circ} \mathrm{C}$ for $1 \mathrm{~h}$; after six times washing, $100 \mu \mathrm{L}$ of TMB solution were incubated at $37^{\circ} \mathrm{C}$ for $15 \mathrm{~min}$; the reaction was then terminated by adding $50 \mu \mathrm{L}$ of $2 \mathrm{M} \mathrm{H}_{2} \mathrm{SO}_{4}$ and the absorbance values was detected at $450 \mathrm{~nm}$.

Preparation of contaminated agricultural products samples for sandwich ELISA analysis. To determine the limit of quantification, $0.1 \mathrm{~g}$ of grinded peanut or maize suspended in $10 \mathrm{~mL}$ PBST was then 10 -fold diluted and mixed with different concentrations of mycelia ranging from $10^{-2}$ to $10^{4} \mu \mathrm{g} \mathrm{mg}^{-1}$, a $100 \mu \mathrm{L}$ homogenates was added into plate wells for sandwich ELISA analysis.

For analysis of the feasibility of nanobodies combined with polyclonal antibody for detecting Aspergillus-infected sample, sandwich ELISA was used to detect naturally infected peanut and maize samples collected from different areas and 4 samples inoculated with A. flavus and A. parasiticus, respectively (Table 3).

Determination of aflatoxins in agricultural products samples. The method was described by Chen et al. ${ }^{33}$. Briefly, aflatoxins in peanuts or maizes were extracted and cleaned up using the AOAC method $991.31^{34}$. Aflatoxin immunoaffinity columns (IACs), with column capacity of $2000 \mathrm{ng}$, were made, utilising the antibody-amino silica gel microparticle ${ }^{35,36}$. Quantitative analysis of aflatoxins was performed by Agilent 1220 HPLC, equipped with a fluorescence detector (FLD). A C18 analytical column $(15 \mathrm{~cm} \times 4.6 \mathrm{~mm} \times 5 \mu \mathrm{m})$ and Romer Derivatisation Unit were used in the system.

\section{References}

1. Smith, J. E. \& Moss, M. O. Mycotoxins. Formation, analysis and significance. (John Wiley \& Sons Ltd., 1985).

2. Shane, S. M., Lasher, H. N. \& Paxton, K. W. Economic impact of infectious bursal disease. International symposium on infectious bursal disease and chicken infectious anaemia, Rauischholzhausen, Germany, 21-24 June, 196-205 (1994).

3. Tsai, G. J. \& Cousin, M. A. Enzyme-linked immunosorbent assay for detection of molds in cheese and yogurt. J. Dariy Sci. 73, 3366-3378 (1990).

4. Ruiter, G. A. d., Hoopman, T., Lugt, A. W. v. d., Notermans, S. H. W. \& Nout, M. J. R. Immunochemical detection of Mucorales species in foods. (Elsevier Science Publishers, 1992).

5. Horst, M. v. d., Samson, R. A. \& Karman, H. Comparison of two commercial kits to detect moulds by latex agglutination. (Elsevier Science Publishers, 1992).

6. Yong, R. K. \& Cousin, M. A. Nonspecific enzyme-linked immunosorbent assay for molds in foods. J. Food Sci. 60, 1357-1363 (1995).

7. Notermans, S., Heuvelman, C. J., Egmond, H. P. V., Paulsch, W. E. \& Besling, J. R. Detection of mold in food by enzyme-linked immunosorbent assay. J. Food Protect. 49, 786-791 (1986).

8. Widershain, G. Y. The ELISA Guidebook. Biochemistry (Moscow) 74, 1296-1296 (2009).

9. Meirelles, P. G. et al. Detection of Fusarium sp contamination in corn by enzyme-linked immunosorbent assay. Food Agric. Immunol. 17, 79-89 (2006).

10. Candlish, A. A. G., Wibowo, M. S. \& Smith, J. E. Immunoassay identification of Aspergillus flavus using monoclonal antibodies raised to the whole cell extracts. Biotechnol. Tech. 11, 21-24 (1997).

11. Thornton, C. R., Slaughter, D. C. \& Davis, R. M. Detection of the sour-rot pathogen Geotrichum candidum in tomato fruit and juice by using a highly specific monoclonal antibody-based ELISA. Int. J. Food Microbiol. 143, 166-172 (2010).

12. Yajima, W., Rahman, M. H., Das, D., Suresh, M. R. \& Kav, N. N. V. Detection of sclerotinia sclerotiorum using a monomeric and dimeric single-chain fragment variable (scFv) antibody. J. Agr. Food. Chem. 56, 9455-9463 (2008).

13. Schutte, M. et al. Identification of a putative Crf splice variant and generation of recombinant antibodies for the specific detection of Aspergillus fumigatus. PLoS one. e6625 (2009).

14. Xue, S. et al. Chicken single-chain antibody fused to alkaline phosphatase detects Aspergillus pathogens and their presence in natural samples by direct sandwich enzyme-linked immunosorbent assay. Anal. Chem. 85, 10992-10999 (2013).

15. Hamers, R. et al. Humoral antibodies in camels. Resistance or tolerance of animals to disease and veterinary epidemiology and diagnostic methods. 67 (1993).

16. Muyldermans, S., Atarhouch, T., Saldanha, J., Barbosa, J. A. \& Hamers, R. Sequence and structure of VH domain from naturally occurring camel heavy chain immunoglobulins lacking light chains. Protein Engineering, Design and Selection 7, 1129-1135 (1994).

17. Muyldermans, S. et al. Camelid immunoglobulins and nanobody technology. Vet. Immunol. Immunopathol. 128, 178-183 (2009).

18. Nguyen, V. K., Desmyter, A. \& Muyldermans, S. Functional heavy-chain antibodies in Camelidae. Adv. Immunol. 79, 261-296 (2001).

19. Maass, D. R., Sepulveda, J., Pernthaner, A. \& Shoemaker, C. B. Alpaca (Lama pacos) as a convenient source of recombinant camelid heavy chain antibodies (VHHs). J. Immunol. Methods. 324, 13-25 (2007).

20. Wörn, A. \& Plückthun, A. Stability engineering of antibody single-chain Fv fragments. J. Mol. Biol. 305, 989 (2001).

21. Glockshuber, R. et al. A comparison of strategies to stabilize immunoglobulin Fv fragments. Biochemistry 29, 1362-1367 (1990).

22. Kim, H. J. et al. Isolation of alpaca anti-hapten heavy chain single domain antibodies for development of sensitive immunoassay. Anal. Chem. 84, 1165-1171 (2012).

23. van Houwelingen, A. et al. Generation of recombinant alpaca VHH antibody fragments for the detection of the mycotoxin ochratoxin A. World Mycotoxin J. 1, 407-417 (2008).

24. Tabares-da Rosa, S. et al. Competitive selection from single domain antibody libraries allows isolation of high-affinity antihapten antibodies that are not favored in the llama immune response. Anal. Chem. 83, 7213-7220 (2011).

25. Wang, Y. R. et al. Isolation of Alpaca Anti-ldiotypic Heavy-Chain Single-Domain Antibody for the Aflatoxin Immunoassay. Anal. Chem. 85, 8298-8303 (2013). 
26. He, T. et al. Nanobody-based enzyme immunoassay for aflatoxin in agro-products with high tolerance to cosolvent methanol. Anal. Chem. 86, 8873-8880 (2014).

27. Muruganandam, A., Tanha, J., Narang, S. \& Stanimirovic, D. Selection of phage-displayed llama single-domain antibodies that transmigrate across human blood-brain barrier endothelium. Faseb Journal Official Publication of the Federation of American Societies for Experimental Biology. 16, 240-242 (2002).

28. Abulrob, A., Sprong, H., Henegouwen, P. \& Stanimirovic, D. The blood-brain barrier transmigrating single domain antibody: mechanisms of transport and antigenic epitopes in human brain endothelial cells. J Neurochem. 95, 1201-1214 (2005).

29. Priyadarshini, E. \& Tulpule, P. G. Relationship between fungal growth and aflatoxin production in varieties of maize and groundnut. J. Agr. Food. Chem. 26, 249-252 (1978).

30. Clark, M. F. \& Adams, A. N. Characteristics of the microplate method of enzyme-linked immunosorbent assay for the detection of plant viruses. J. Gen. Virol. 34, 475-483 (1977).

31. Harvey, J. Pesticide analytical Methodology. Anal. Chem. (1980).

32. $\mathrm{Hu}, \mathrm{Z}$. Q. et al. Generation of a highly reactive chicken-derived single-chain variable fragment against Fusarium verticillioides by phage display. Int. J. Mol. Sci. 13, 7038-7056 (2012).

33. Chen, R. et al. Effect of ozone on aflatoxins detoxification and nutritional quality of peanuts. Food. Chem. 146, 284-288 (2014).

34. AOAC International Method 991.31-1994. Aflatoxins in corn, raw peanuts, and peanut butter immunoaffinity column (Aflatest) method. AOAC International Official Methods of Analysis. Gaithersburg, Maryland, USA (2002).

35. Ma, F. et al. Preparation of an immunoaffinity column with amino-silica gel microparticles and its application in sample cleanup for aflatoxin detection in agri-products. Molecules 18, 2222-2235 (2013).

36. Xiao, Z. J. et al. Development of a new high performance immunoaffinity micro-column for aflatoxin $B_{1}$ purification in crain and oil. Chinese Journal of Oil Crop Sciences 28, 335-341 (2006).

\section{Acknowledgements}

This work was supported by the National Natural Science Foundation of China $(31471650,31640062)$ and the Special Fund for Agro-scientific Research in the Public Interest (201303088).

\section{Author Contributions}

P.L. and Q.Z. designed the study. T.W. conducted the study and wrote the main manuscript text. T.W. and Q.Z. analyzed the data and prepared all of figures. W.Z., Z.Z., T.W. and T.H. helped to interpret the results and revise the manuscript. All authors reviewed and approved the final manuscript. P.L. and Q.Z. had primary responsibility for final content.

\section{Additional Information}

Competing Interests: The authors declare that they have no competing interests.

Publisher's note: Springer Nature remains neutral with regard to jurisdictional claims in published maps and institutional affiliations.

(c) (i) Open Access This article is licensed under a Creative Commons Attribution 4.0 International

License, which permits use, sharing, adaptation, distribution and reproduction in any medium or format, as long as you give appropriate credit to the original author(s) and the source, provide a link to the Creative Commons license, and indicate if changes were made. The images or other third party material in this article are included in the article's Creative Commons license, unless indicated otherwise in a credit line to the material. If material is not included in the article's Creative Commons license and your intended use is not permitted by statutory regulation or exceeds the permitted use, you will need to obtain permission directly from the copyright holder. To view a copy of this license, visit http://creativecommons.org/licenses/by/4.0/.

(c) The Author(s) 2017 